\title{
Transient Stability Analysis of Synchronous Generator in Power System with Renewable Power Sources
}

\section{Installed}

\author{
Masaki Yagami ${ }^{1}$, Yoshihiro Ichinohe ${ }^{1}$, Yohichiro Kojima ${ }^{1}$, Kenji Misawa ${ }^{1}$ and Junji Tamura ${ }^{2}$ \\ 1. Department of Electrical and Electronic Engineering, Hokkaido University of Science, Sapporo 006-8585, Japan \\ 2. Department of Electrical and Electronic Engineering, Kitami Institute of Technology, Kitami 090-8507, Japan
}

\begin{abstract}
The impact of large-scale grid-connected renewable power sources, such as wind generators and solar photovoltaic systems, on transient stability of synchronous generators is discussed in this paper. The permanent magnet synchronous generator with variable speed wind turbine is used in the simulation analysis as a wind generator model. The transient stability analysis is performed for IEEE 9-bus system model with high-penetration renewable power sources. The effect of FRT (fault ride-through) capability implemented for each power source on the transient stability is investigated.
\end{abstract}

Key words: Fault ride-through, variable speed wind generator, photovoltaic, synchronous generator, transient stability.

\section{Introduction}

In Japan, with the increasing concerns about global warming and the start of the FIT (Feed-in Tariff) program in July 2012, the amount of renewable power sources, such as WG (wind generators) and solar photovoltaic (PV) systems, has been increasing. At the end of 2015, the total cumulative installed capacity of WG and PV in Japan reached 3.0 GW [1] and 34.2 GW [2] (around $0.5 \%$ and $3.5 \%$ of the total power supply) respectively. From the viewpoint of environmental conservation, the amount of the grid-connected renewable power sources is expected to increase continuously. However, the expanding installation of renewable power sources has a significant impact on power system dynamics and stability $[3,4]$.

Currently, most of WG and PV systems do not have FRT (fault ride-through) capability. Their impact on the stability may become more serious when the considerable amounts of WG and PV systems are disconnected simultaneously during voltage sag.

Corresponding author: Masaki Yagami, Ph.D., professor, research fields: power system stability and flexible AC transmission system (FACTS).
Moreover, with the increasing of capacity of renewable power sources in the power system, the total capacity of conventional synchronous generators needs to be reduced relatively. This leads to the higher generator reactance and the fewer frequency control generators, and hence the power system transient stability may negatively be affected.

In this work, the potential impact of large-scale grid-connected WG or PV systems on the transient stability of the conventional synchronous generator is assessed by a numerical simulation analysis using PSCAD/EMTDC software. The PMSG (permanent magnet synchronous generator) with VSWG (variable speed wind turbine) is used in the simulation analysis as a WG model. The simulation analysis is performed for IEEE 9-bus system model with each power source installed. The effect of FRT capability implemented for each power source on the transient stability is investigated.

\section{Simulation Model}

\subsection{Power System Model}

Fig. 1 shows the power system model [5], which is 


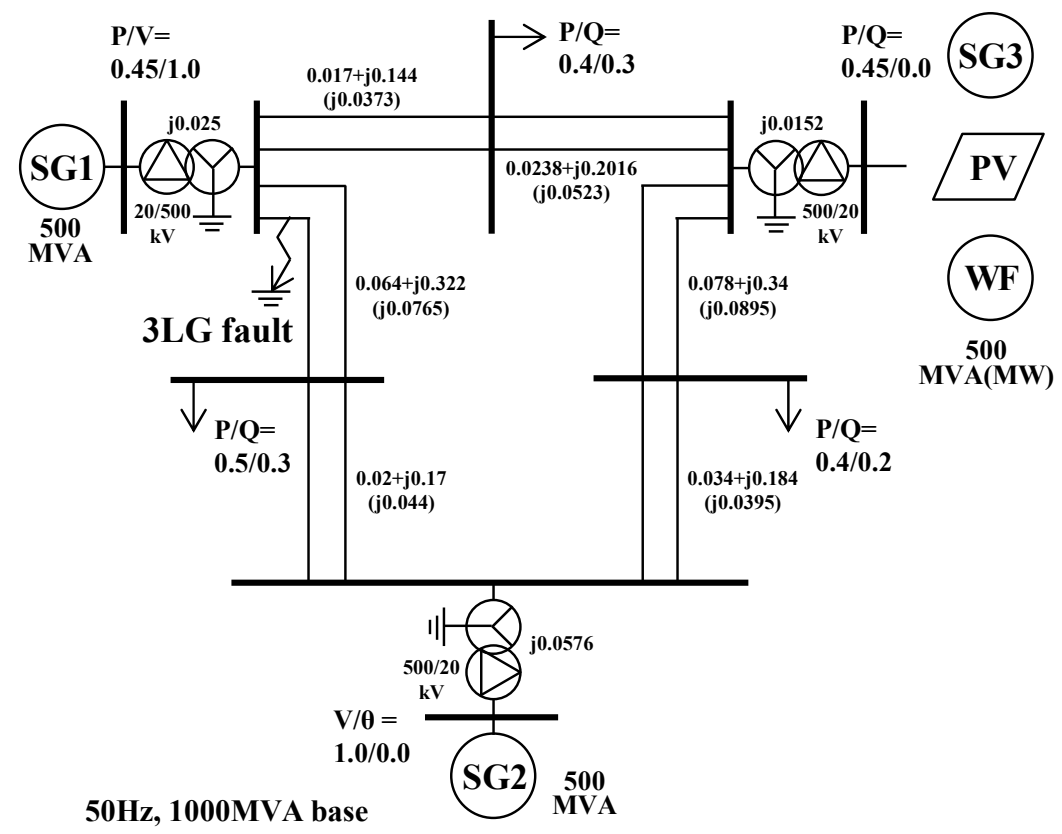

Fig. 1 Power system model.

Table 1 Synchronous generator parameters.

\begin{tabular}{llllll}
\hline \multicolumn{5}{c}{ Generator parameters } \\
\hline & SG1 & SG2, SG3 & & SG1 & SG2, SG3 \\
\hline$R_{a}(\mathrm{pu})$ & 0.003 & 0.004 & $X_{d}{ }^{\prime \prime}(\mathrm{pu})$ & 0.171 & 0.134 \\
$X_{l}(\mathrm{pu})$ & 0.102 & 0.078 & $X_{q}{ }^{\prime}(\mathrm{pu})$ & 0.171 & 0.134 \\
$X_{d}(\mathrm{pu})$ & 1.651 & 1.22 & $T_{d o}{ }^{\prime}(\mathrm{s})$ & 5.9 & 8.97 \\
$X_{q}(\mathrm{pu})$ & 1.59 & 1.16 & $T_{q o}{ }^{\prime}(\mathrm{s})$ & 0.535 & 1.50 \\
$X_{d}{ }^{\prime}(\mathrm{pu})$ & 0.232 & 0.174 & $T_{d o}{ }^{\prime}(\mathrm{s})$ & 0.033 & 0.033 \\
$X_{q}{ }^{\prime}(\mathrm{pu})$ & 0.38 & 0.25 & $T_{q o}{ }^{\prime}{ }^{(\mathrm{s})}$ & 0.078 & 0.141 \\
$H(\mathrm{~s})$ & 3.0 & & & & \\
\hline
\end{tabular}

composed of three power sources: one synchronous generator of 500 MVA (SG1), another synchronous generator of 500 MVA (SG2), and the third source, which is one of a large-scale PV plant of $500 \mathrm{MW}$ (PV) or a wind farm of 500 MVA (WF) composed of one hundred VSWGs $(5 \mathrm{MW} \times 100)$ or a third synchronous generator of 500 MVA (SG3). Each power source is connected through step up transformer to $500 \mathrm{kV}$ bus and double circuit transmission lines. The impedances and the initial power flows are shown in per unit values on the power system base of 1,000 MVA in the figure.

The parameters used for each synchronous generator are shown in Table 1. AVR (automatic voltage regulator) [6] and governor control systems shown in Fig. 2 are included in each synchronous generator model. In the cases with $\mathrm{PV}$ and $\mathrm{WF}$ installed, the existence of FRT capability is considered for each power source. FRT characteristic considered in this work is simple. The power converter with FRT capability maintains connection to the grid even if its terminal voltage is dropped. On the other hand, the power converter without FRT capability is disconnected from the grid when its terminal voltage drops below $70 \%$ of the nominal voltage [7].

In the power system model, a symmetrical $3 \mathrm{LG}$ (three-line-to-ground) fault is assumed as network disturbance. The fault occurs near SG1 at $0.1 \mathrm{~s}$, the circuit breakers on the faulted lines are opened at 0.17 $\mathrm{s}$, and at $1.17 \mathrm{~s}$, they are reclosed. 


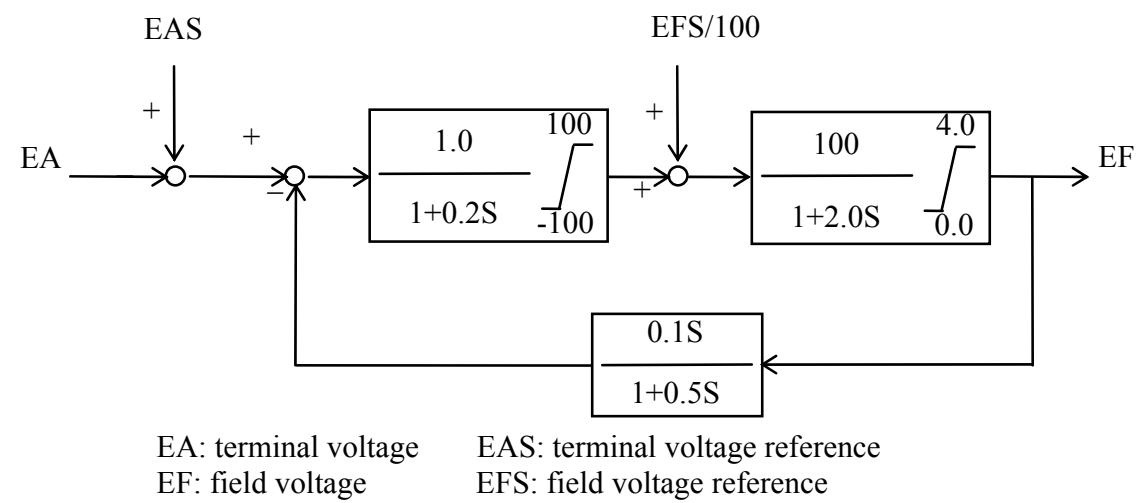

(a) AVR

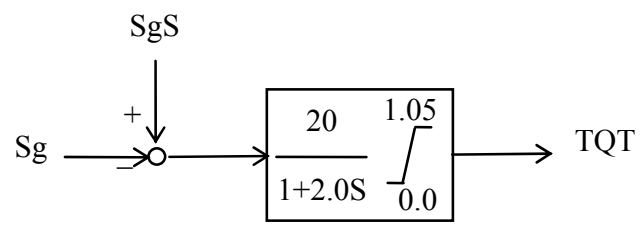

Sg: generator speed TQT: turbine torque
$\mathrm{SgS}$ : generator speed reference

(b) Governor

Fig. 2 AVR and governor models.

\subsection{PV System Model}

PV system model is shown in Fig. 3. It consists of PV module and inverter. The PV module is represented with a voltage source, and hence the PV output is constant under the steady state. This means irradiation and PV cell temperature are constant during the simulation period. In general, transient stability is analyzed in a time window of a few seconds to several tens of seconds. The assumption, therefore, may be valid for the transient stability analyses.

The genetic PWM (pulse-width modulation) voltage source converter is used as PV inverter. The inverter controls the active and reactive power injected from the PV module to the system. To maintain the active and reactive power at the reference set points, the currents of the inverter are controlled by using vector control technique. The current limitation for over current is not considered in this model. Currently, most of the PV inverters are designed to operate at unity power factor [7], and therefore the reference value of the reactive power is set to zero in each case.

\subsection{VSWG System Model}

A simplified VSWG model composed of a three phase current source [8] shown in Fig. 4 is used in this paper. The simplified model is effective on the analysis of the power system with a large number of wind generators which cannot be analyzed by using the detailed model. In this work, WF is composed of one hundred VSWGs each rated at $5 \mathrm{MW}$. VSWG parameters are shown in Table 2.

The mechanical output power of wind turbine captured from the wind power can be calculated as follows:

$$
P_{w}=\frac{1}{2} \rho \pi R^{2} V_{w}^{3} C_{p}(\lambda, \beta)
$$

where, $P_{w}$ is the captured wind power, $\rho$ is the air density, $R$ is the radius of rotor blade, $V_{w}$ is wind speed, $C_{p}$ is the power coefficient, $\lambda$ is tip speed ratio and $\beta$ is blade pitch angle. In this simulation, $V_{w}$ is kept constant at $11.1(\mathrm{~m} / \mathrm{s})$ at which the VSWG reference power is $0.9 \mathrm{pu}$ (generator capacity base), based on the assumption that the wind speed does not change dramatically within this small time duration. 


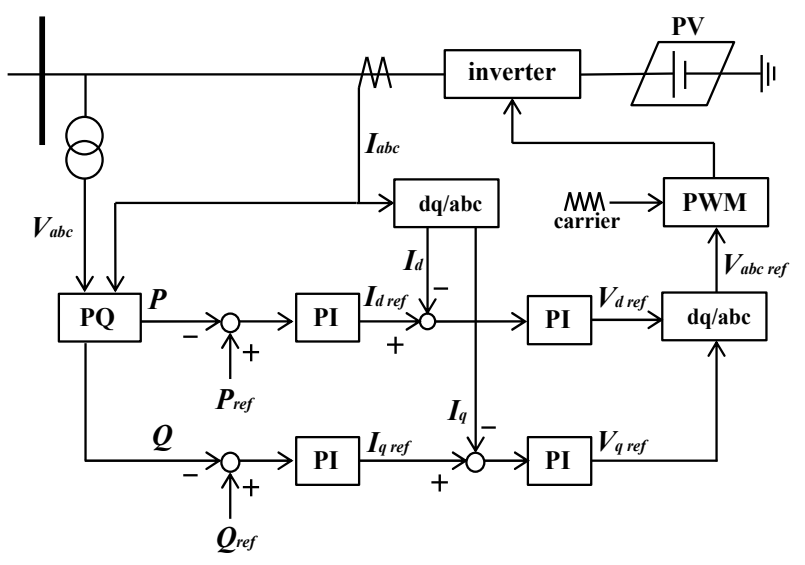

Fig. 3 PV system model.

The drive train composed of wind turbine, shaft and generator is modeled using the single rotating mass model:

$$
T_{m}-T_{e}=J_{t} \frac{d \omega_{r}}{d t}
$$

where, $T_{m}, T_{e}, J_{t}$ and $\omega_{r}$ are mechanical torque, electrical torque, total moment of inertia of entire mechanical system, and rotor speed of the wind turbine respectively.

The dynamic model of PMSG in the d-q rotating reference frame is expressed by the following equations.

$$
\begin{gathered}
V_{s d}=R_{s} I_{s d}+L_{s d} \frac{d I_{s d}}{d t}-\omega_{e} L_{s q} I_{s q} \\
V_{s q}=R_{s} I_{s q}+L_{s q} \frac{d I_{s q}}{d t}+\omega_{e} L_{s d} I_{s d}+\omega_{e} \psi_{m}
\end{gathered}
$$

where $V_{s d}$ and $V_{s q}$ are stator voltages, $R_{s}$ is the stator winding resistance, $I_{s d}$ and $I_{s q}$ are stator currents, $\omega_{e}$ is the generator rotational speed, $L_{s d}$ and $L_{s q}$ are the synchronous inductances of stator winding, and $\psi_{m}$ is the flux of permanent magnet.

Active and reactive powers of PMSG are expressed as follows:

$$
\begin{gathered}
P_{s}=V_{s d} I_{s d}+V_{s q} I_{s q} \\
Q_{s}=V_{s q} I_{s d}-V_{s d} I_{s q}
\end{gathered}
$$

The electrical torque of PMSG can be expressed as follows:
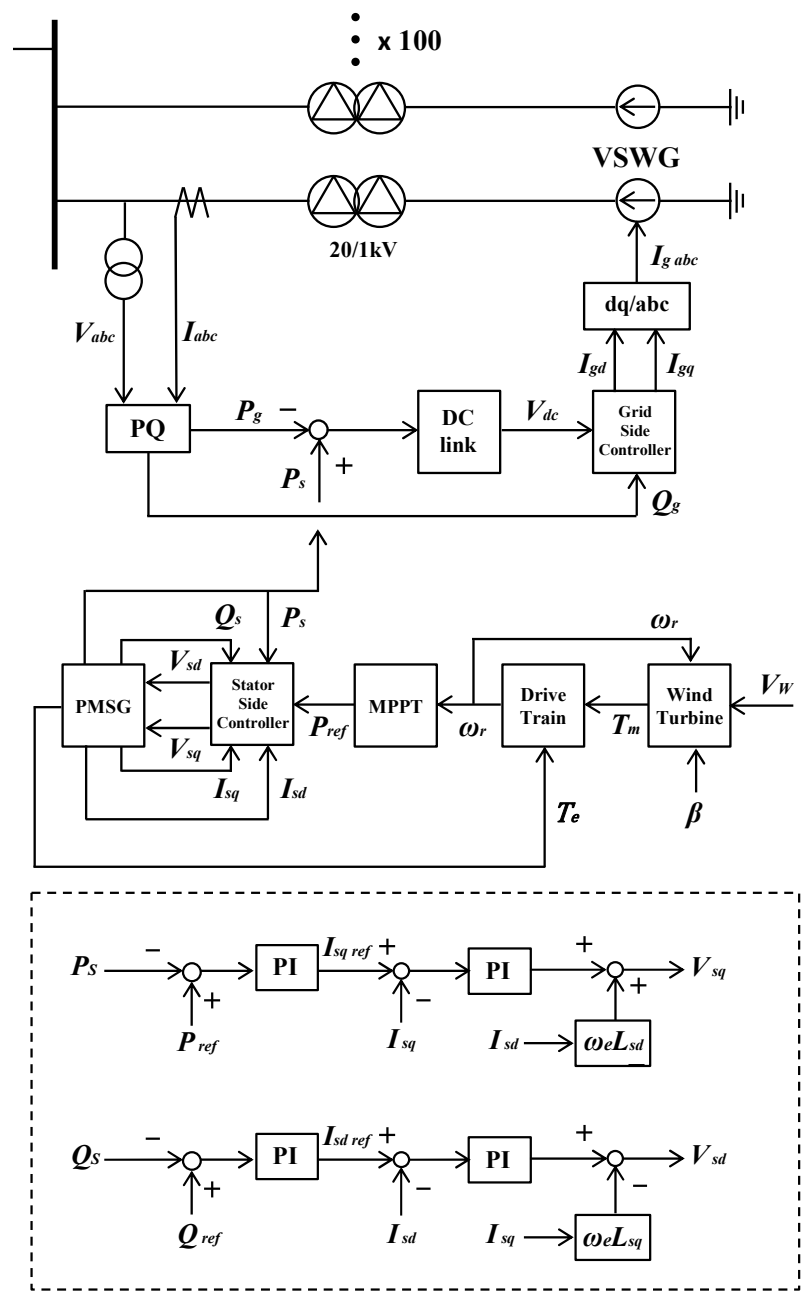

Stator side controller.

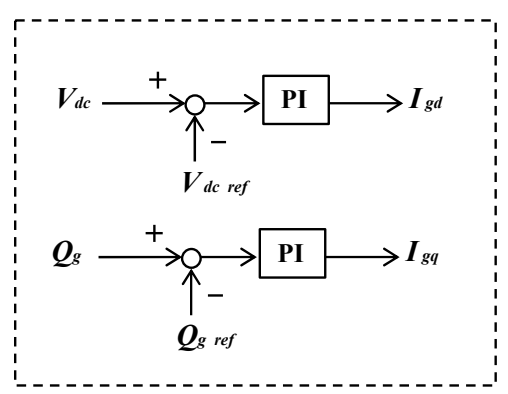

Grid side controller.

Fig. 4 VSWG system model.

$$
T_{e}=p\left(\psi_{m} I_{s q}+\left(L_{s d}-L_{s q}\right) I_{s d} I_{s q}\right)
$$

where, $p$ is the number of pole pairs. The dynamic behavior of DC capacitor voltage $\left(V_{d c}\right)$ can be expressed by the following equation if the power losses of DC-link are neglected. 
Table 2 VSWG parameters.

\begin{tabular}{|c|c|c|}
\hline \multicolumn{3}{|c|}{ VSWG parameters } \\
\hline \multirow{7}{*}{ Wind turbine } & $R(\mathrm{~m})$ & 60 \\
\hline & $V_{w}(\mathrm{~m} / \mathrm{s})$ & 11.1 \\
\hline & $\omega_{r}(\mathrm{rad} / \mathrm{s})$ & 1.51 \\
\hline & $C_{\text {popt }}$ & 0.48 \\
\hline & $\lambda_{\text {opt }}$ & 8.2 \\
\hline & $\rho\left(\mathrm{kg} / \mathrm{m}^{3}\right)$ & 1.225 \\
\hline & $J_{t}\left(\mathrm{kgm}^{2}\right)$ & $49.5 \times 10^{6}$ \\
\hline \multirow{8}{*}{ PMSG } & $P_{s}(\mathrm{MW})$ & 5 \\
\hline & $V_{s}(\mathrm{kV})$ & 1.0 \\
\hline & $R_{s}(\Omega)$ & 0.004 \\
\hline & $L_{s d}(\mathrm{mH})$ & 1.528 \\
\hline & $L_{s q}(\mathrm{mH})$ & 1.21 \\
\hline & $\psi_{m}(\mathrm{~Wb})$ & 11.255 \\
\hline & $C_{d c}(\mu \mathrm{F})$ & 2,500 \\
\hline & $V_{d c}(\mathrm{kV})$ & 1.75 \\
\hline
\end{tabular}

where, $C_{d c}$ is the value of DC-link capacitor and $P_{g}$ is active power delivered to the grid.

\section{Simulation Results}

\subsection{Simulation Results in Case with FRT Implemented}

First, the transient stability of SG1 in the power system with each power source installed with FRT capability implemented is discussed. In the case with FRT capability implemented, the power supply from each power source (SG3, PV, WF) is maintained after the fault.

Figs. 5 and 6 show the responses of phase angle and kinetic energy of SG1 respectively. The phase angles shown are displacement angle with respect to the phase angle of the swing generator SG2. As shown in Fig. 5, the first peaks of the phase angle swings of SG1 in the cases with PV and WF installed are restrained more than that in the case with SG3 installed. Namely, the risk of out-of-step of the synchronous generator becomes low in the power system with PV or WF installed with FRT capability implemented. However, the kinetic energy swings of SG1 are larger than that in the case with SG3 installed as shown in Fig. 6. The acceleration or deceleration of the rotor causes severe mechanical stresses.
Figs. 7-9 show the responses of active power, reactive power and terminal voltage of SG1 respectively. The active power in the case with SG3 installed rises up immediately after the fault clearing. This is because, as shown in Fig. 9, the terminal voltage of SG1 rises also up immediately after the fault clearing. As the period of condition of the unbalance between the mechanical input power and the electrical output power of SG1 is short, SG1 is subjected to the smaller accelerating power. On the other hand, in the case with PV installed, it takes time to recover the active power and the terminal voltage after the fault clearing. Therefore, in the case with PV installed, SG1 is subjected to the larger accelerating power, and hence the kinetic energy swing becomes large.

Figs. 10-13 show the responses of active power, reactive power, terminal voltage of each power source and DC-link voltage of VSWG. In the case with SG3 installed, as shown in Fig. 11, SG3 supplies a sufficient reactive power after the fault. As a result, the terminal voltage of SG3 rises up significantly after the fault clearing. The reactive power of WF also increased after the fault. Moreover, as shown in Fig. 13, DC-link voltage of the grid side converter rises up after the fault due to the power unbalance between the generator side converter and the grid side converter during the fault. For these reasons, the magnitude of voltage sag of WF during the fault is small. On the other hand, as shown in Fig. 12, the magnitude of voltage sag of PV is large. This is because the reactive power of PV cannot increase significantly due to the constant power control of the PV inverter.

\subsection{Simulation Results in Case without FRT Implemented}

Next, the transient stability of SG1 in the power system with each power source (PV, WF) installed without FRT capability implemented is discussed. It is assumed that each power source is disconnected from the grid when its terminal voltage drops below $70 \%$ of the nominal voltage. 
Renewable Power Sources Installed

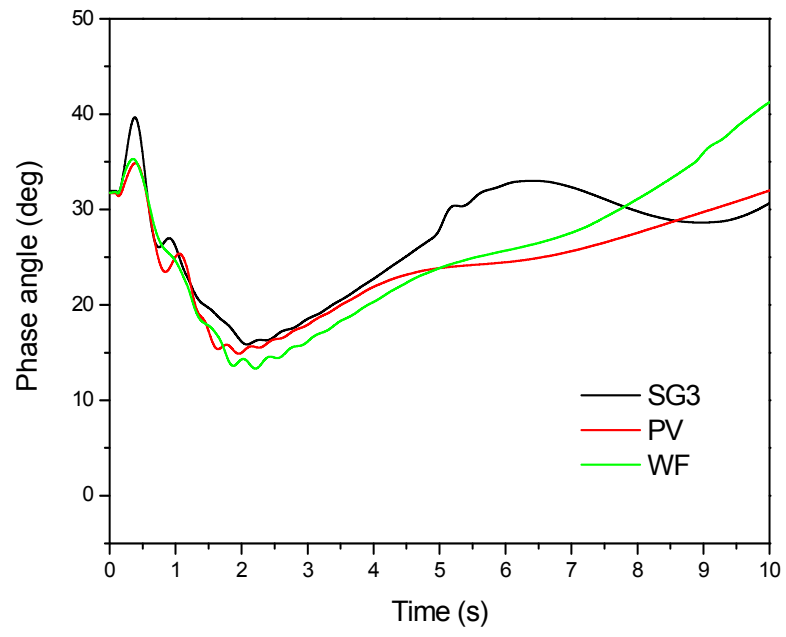

Fig. 5 Phase angle of SG1 in case with each power source with FRT.

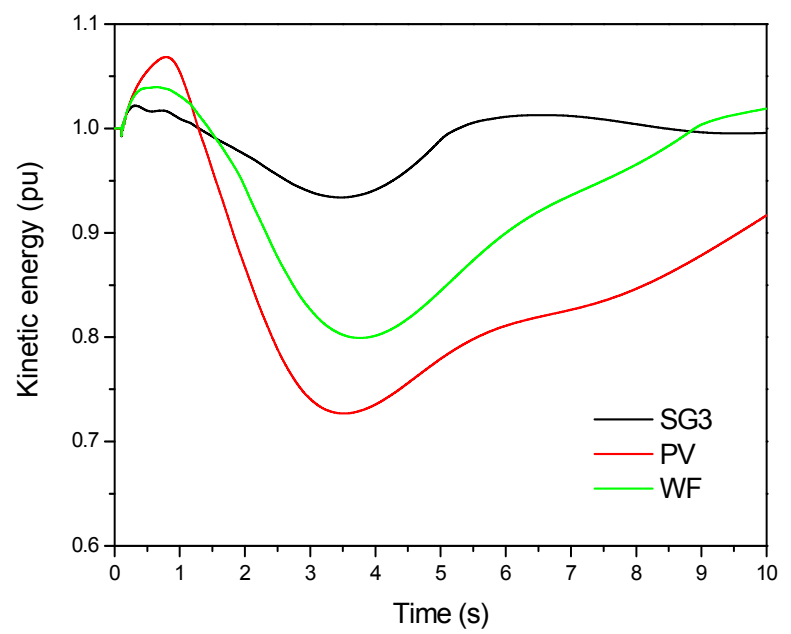

Fig. 6 Kinetic energy of SG1 in case with each power source with FRT.

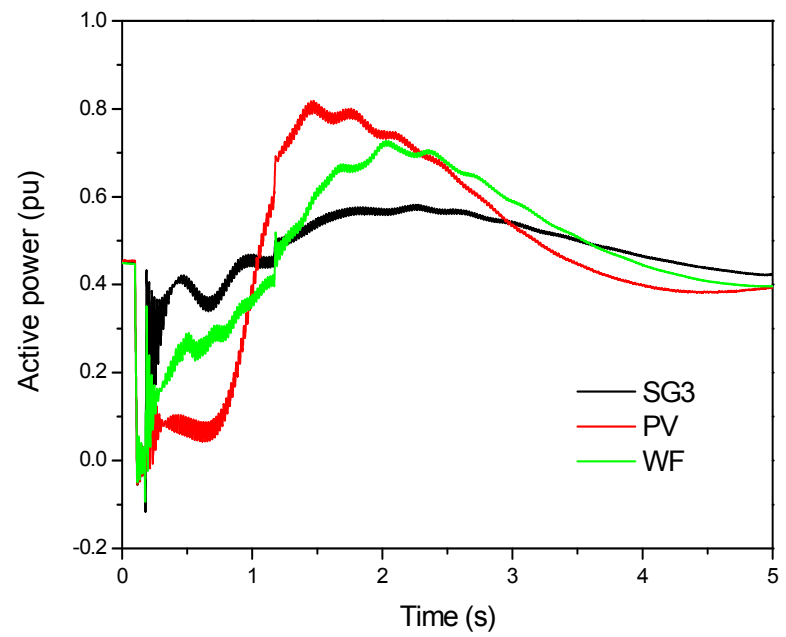

Fig. 7 Active power of SG1 in case with each power source with FRT.

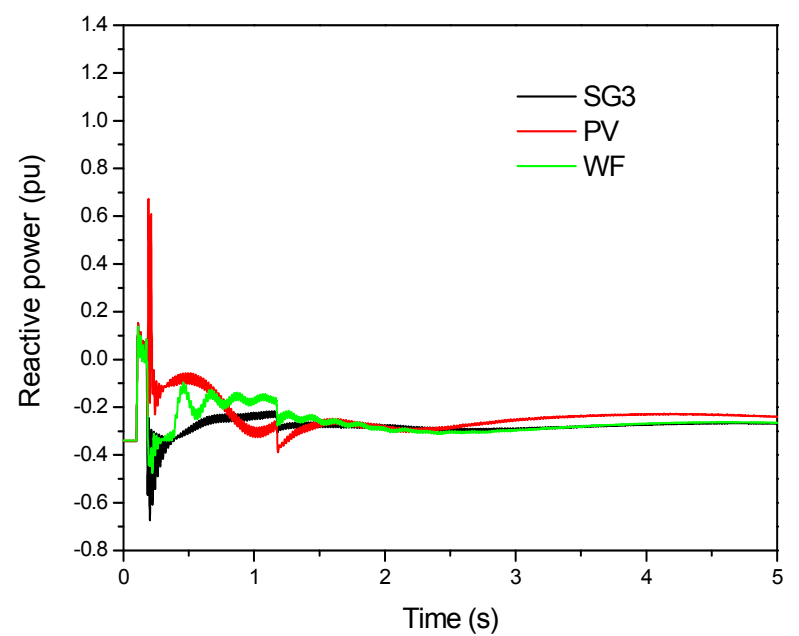

Fig. 8 Reactive power of SG1 in case with each power source with FRT.

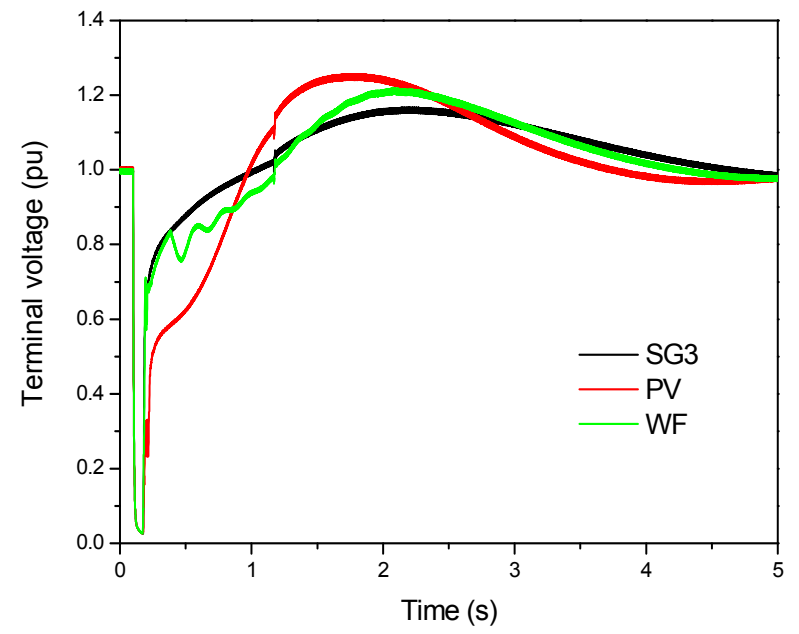

Fig. 9 Terminal voltage of SG1 in case with each power source with FRT.

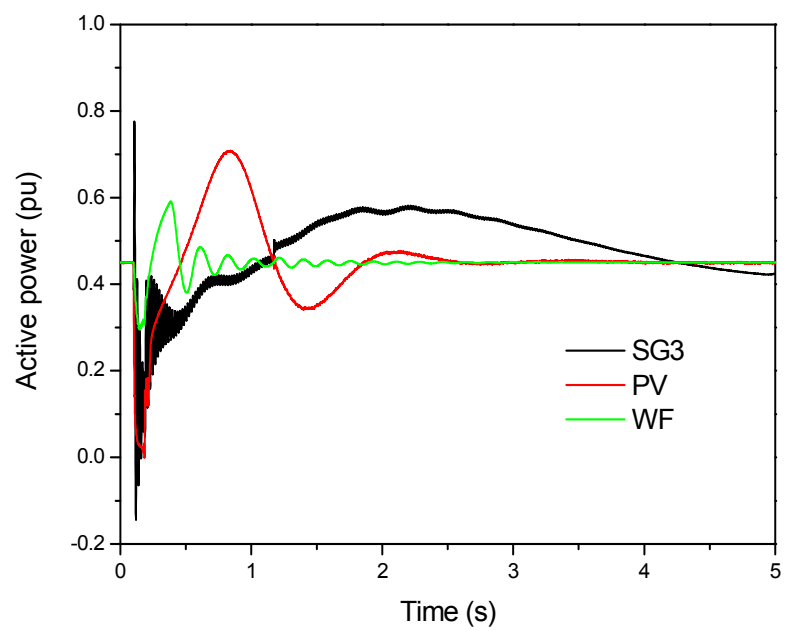

Fig. 10 Active power of each power source. 
Renewable Power Sources Installed

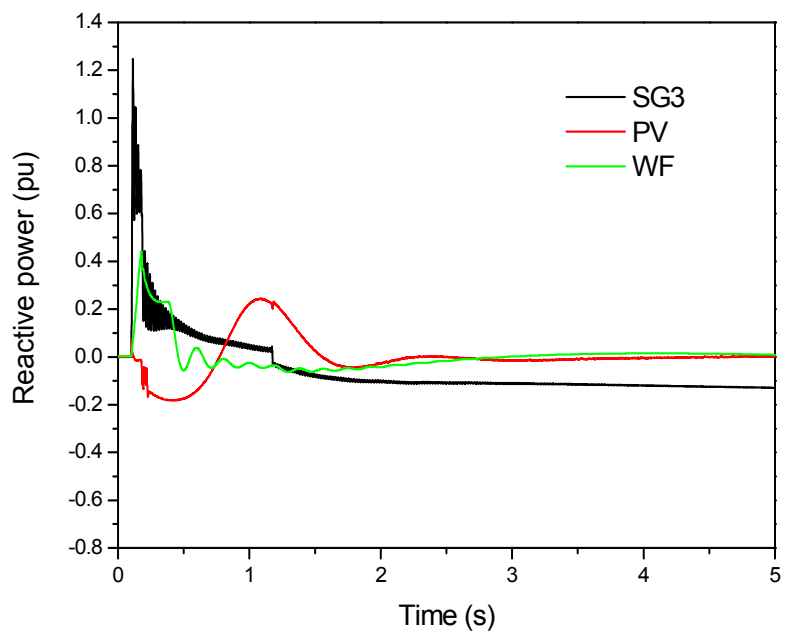

Fig. 11 Reactive power of each power source.

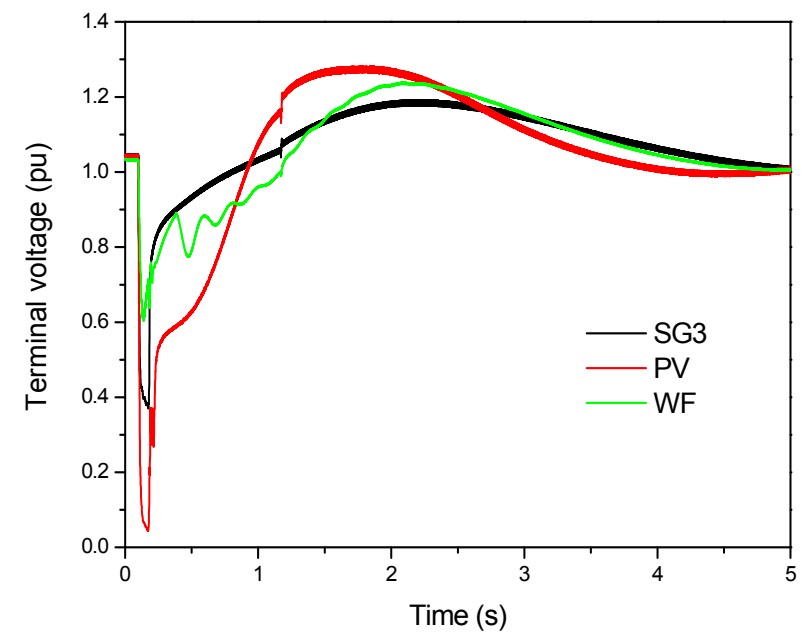

Fig. 12 Terminal voltage of each power source.

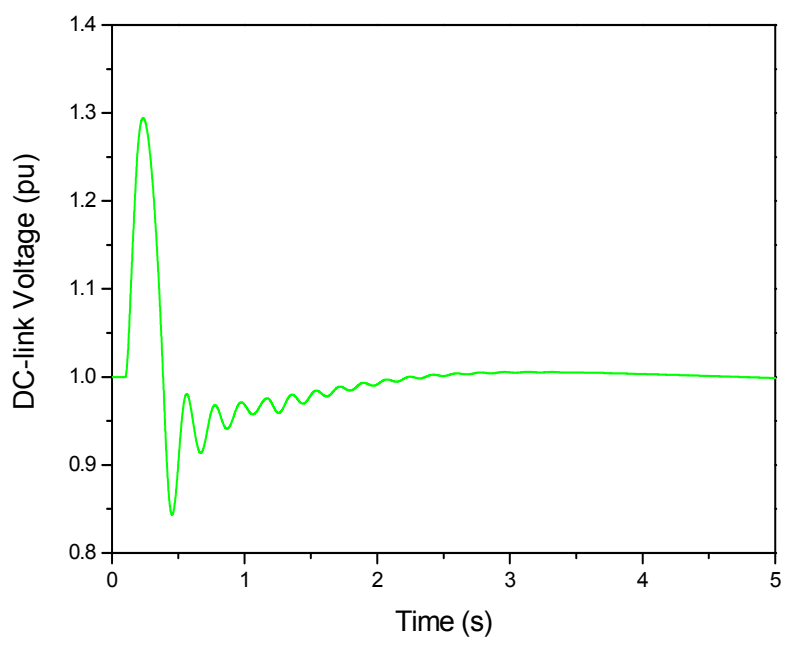

Fig. 13 DC-link voltage of VSWG.

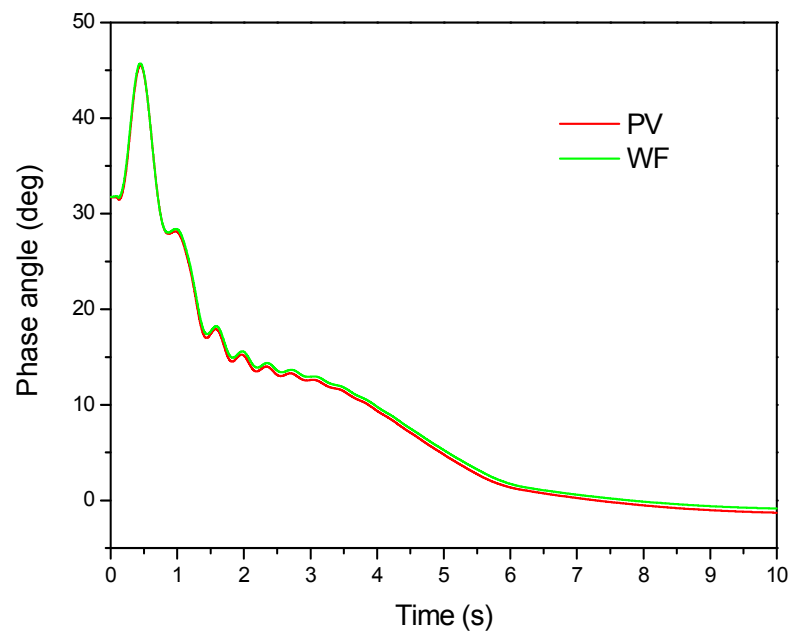

Fig. 14 Phase angle of SG1 in case with each power source without FRT.

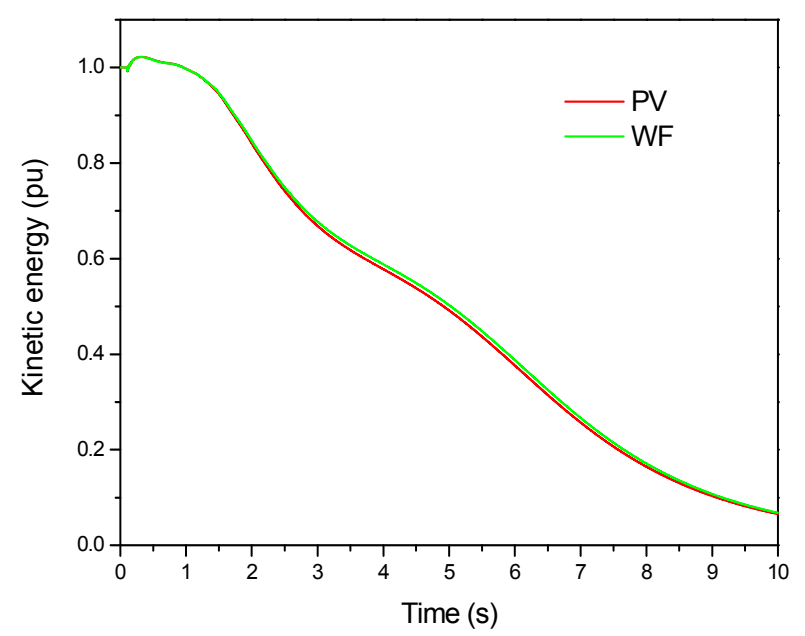

Fig. 15 Kinetic energy of SG1 in case with each power source without FRT.

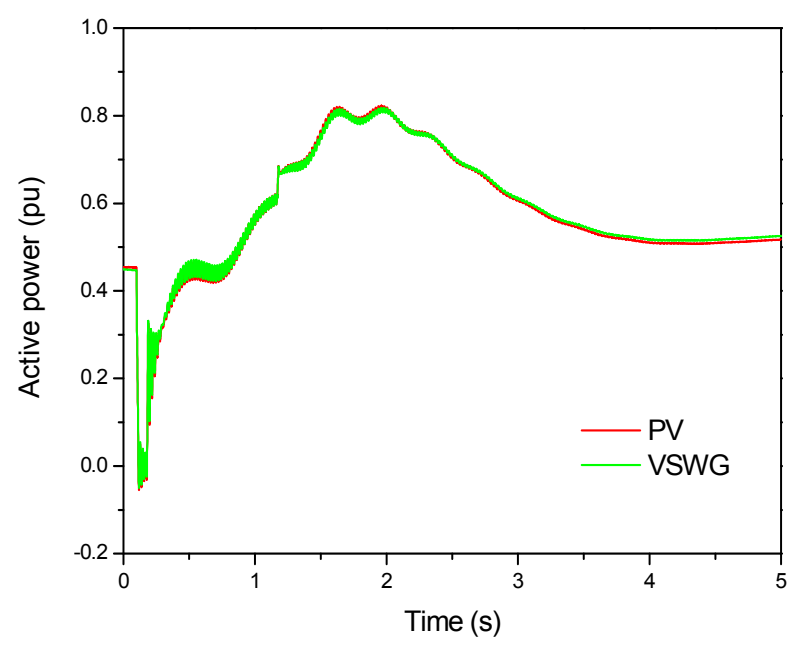

Fig. 16 Active power of SG1 in case with each power source without FRT. 
Figs. 14 and 15 show the responses of phase angle and kinetic energy of SG1 respectively. In both cases, as the terminal voltages drop below the specified value, each power source is disconnected immediately from the grid after the fault. Therefore, these transient simulations present the almost same results. As shown in Figs. 14 and 15, the phase angles and the kinetic energies of SG1 in both cases decrease toward zero value. Those of SG2 also decrease toward zero value. Namely, SG1 and SG2 go to out-of-step in the decelerating direction. This is because unbalance between the power supply and the demand becomes very large after the disconnection of PV or WF. The disconnection of $\mathrm{PV}$ or WF leads to the power shortage in the power system, and hence the active power of SG1 (and SG2) increases after the disconnection of PV or WF as shown in Fig. 16. However, the prime-mover mechanical power(s) of SG1(and SG2) is(are) restricted by the turbine load limiter, the rotor is subjected to the large decelerating power due to the unbalance between the mechanical input power and the electrical output power. As a result, the kinetic energy stored in the rotor is extremely released, and hence the generator goes to out-of-step in the decelerating direction.

\section{Conclusions}

This paper presents a case study assessing the impact of renewable power sources, such as WG (wind generators) and solar photovoltaic (PV) systems, on the transient stability of conventional synchronous generators. The effect of FRT capability implemented for each power source on the transient stability is investigated.

In the cases that WG and PV systems with FRT capability are installed, the risk of out-of-step of the synchronous generator becomes lower than that in the case with the conventional synchronous generator installed. However, the transient swing of kinetic energy becomes larger.

In the cases that WG and PV systems without FRT capability are installed, especially when their capacities are large relative to the total capacity of power system, the risk of out-of-step of the synchronous generator in the decelerating direction becomes high.

\section{Acknowledgments}

This work was supported by research grant from JSPS (Japan society for the promotion of science) KAKENHI Grant Number 15H03956.

\section{References}

[1] Global Wind Energy Council. 2016. Global Wind Report 2015: 10 .

[2] Photovoltaic Power Systems Programme. 2016. Trends 2016 in Photovoltaic Applications. Report IEA-PVPS T1-30: 20.

[3] Yagami, M., Hasegawa, T., and Tamura, J. 2012. "Transient Stability Assessment of Synchronous Generator in Power System with High-Penetration Photovoltaics." Journal of Mechanics Engineering and Automation 2: 762-8.

[4] Yagami, M., Ishikawa, S., Ichinohe, Y., Misawa, K., and Tamura, J. 2015. "Transient Stability Assessment of Synchronous Generator in Power System with High-Penetration Photovoltaics (Part 2)." Journal of Mechanics Engineering and Automation 5: 401-6.

[5] Anderson, P. M., Fouad, A. A. 2000. Power System Control and Stability. New York: John Wiley \& Sons, Inc.

[6] IEEJ Technical Committee. 1999. Standard Models of Power System. IEEJ Technical report 754.

[7] Kobayashi, H., and Suzuki, A. 2010. Stable Operation Technique for PCS of PV Power Generation at Grid Recovery after Voltage Sag. System Engineering Research Laboratory, R09015.

[8] Rosyadi, M., Umemura, A., Takahashi, R., Tamura, J., and Park, M. 2013. "Dynamic Analysis of Offshore Wind Farm with PM Wind Generators Using Simplified Model." 2013 IEEE PowerTech Conference A5240MR. 